\title{
El genio y lo genuino que hay em nosotros, vigencia del pensamiento educativo em Nietzsche
}

Andrea Marta Díaz Genis

Universidad de la República (Uruguai)

\section{RESUMO}

Este artigo trata da filosofia da educação em Nietzsche, analisada a partir de sua obra de juventude, especialmente Schopenhaner como educador. Analisam-se o sentido e o alcance da educação do gênio e do genuíno e singular que está presente em nós. Investiga-se se há um paralelo entre a educação socrática e a nietzscheana e o papel que em Nietzsche tem a filosofia e o filósofo como pedagogo da humanidade, assumindo como centro o cuidado da vida, a inquietude de si e o conhecimento.

Palavras-chave: gênio; genuíno; autoconhecimento.

\section{RESUMEN}

Este artículo versa sobre la filosofía de la educación en Nietzsche, analizada a partir de su obra de juventud, sobre todo de Schopenhaner como educador. Se analiza el sentido y el alcance de la educación del genio y de lo genuino y singular que hay en nosotros. Se hace un paralelo entre la educación socrática y la nietzscheana, y el papel que en Nietzsche tiene la filosofía y el filósofo como pedagogo de la humanidad, teniendo como centro el cuidado de la vida, la inquietud de sí y el autoconocimiento.

Palabras claves: genio; genuino; autoconocimiento. 
$\mathrm{E}$ 1 pensamiento educativo de Nietzsche se ubica en su obra de juventud y principalmente a su período llamado "intempestivo". Pertenecen a este período la serie de conferencias que imparte en la Universidad de Basilea en los comienzos de 1872 y que luego se publican bajo el título: Sobre el futuro de nuestras instituciones educativas (2011), y su obra intempestiva titulada Consideraciones intempestivas III. Schopenhauer como educador (2011). Es sobre todo basados en esta última obra que vamos a realizar nuestra reflexión. Nietzsche no ha sido destacado como un filósofo de la educación. Sin embargo, nos parece que en su obra está presente la preocupación por lo educativo de una forma muy persistente, profunda y actual como lo mostraremos brevemente en este artículo ( $\sin$ poder profundizar dado la extensión posible de este tipo de trabajo). Nuestro filósofo ha escrito estas dos obras importantes sobre el tema educativo, realizadas precisamente durante el periodo en que era profesor de Basilea. Nietzsche había sido educado en uno de los mejores y exigentes colegios de la época...el Colegio Pforta, donde había aprendido a leer a los clásicos en perfecto griego y latín. Esta característica se hace evidente a la hora exigir rigor en la formación de los estudiantes del bachillerato. El profesor de la Universidad de Basilea se nota preocupado por el destino de la educación de su época, cuestión que refleja de un modo más circunstancial e institucional si se quiere, en Sobre el futuro de nuestras institución educativas y de forma más abstracta y cultural en Schopenhauer como educador, donde encontramos toda una caracterización del genio que es a donde debe propender toda educación en sus niveles más altos. Nos vamos a detener especialmente en el segundo de estos textos en relación al concepto del genio y de lo genuino que hay en nosotros, tal como lo hemos denominado en el título de esta ponencia.

Nietzsche lucha contra la educación de masas y sobre todo contra el Estado puesto a educador. Le interesa el unicum, la singularidad. La diferencia del que sobresale, pero también la diferencia cultivada hacia el interior La cultura trasmitida a través de la educación debe dar las condiciones, por lo tanto, para que surja este unicum dentro y fuera de 
nosotros. Nos parece, que no deja de ser importante e interesante resaltar, que si bien la educación nietzscheana se construye a partir de la idea de un aristocracia espiritual en que sólo unos pocos pueden ser los representantes (de los cuales en Alemania, Goethe y el mismo Schopenhauer son los ejemplares más altos), también se puede hacer una lectura "preexistencialista" de su propuesta educativa, extensible a todos, en tanto que desde de una perspectiva educativa también se promueve la "autenticidad" y lo que nosotros hemos dado en denominar, "lo genuino" que hay en nosotros. Ya al comenzar el texto de Schopenhauer como educador Nietzsche nos dice que el dictado de la propia conciencia nos dice: "sé tu mismo" (p. 749). Puesto que: "Tu no eres nada de lo que ahora haces, nada de lo que ahora opinas, nada de lo que ahora deseas" (p. 750). El ser humano está llamado a ser él mismo, sin embargo, por miedo y pereza el sujeto se va construyendo a partir de disposiciones externas, acomodamientos, va forjándose desde una "corteza sin núcleo" tibia y $\sin$ desarrollo profundo. Esta tendencia a conformar una cultura desde la convención, la moda, el acomodamiento, es algo que ya había criticado en su otra intempestiva titulada De la utilidad y la conveniencia de la Historia para la vida (2011). El hombre de la cultura histórica (básicamente el hombre del siglo XIX, del historicismo aplastante de su época), entiende por cultura la acumulación de conocimientos históricos, la memoria de hechos que le anteceden sin las cuales parecería que no puede funcionar ni vivir. Lo cierto es que la verdadera cultura, entendida como creación, necesita del olvido o de cierta cuota del olvido, para obtener acopio de energía, y permitirse decir lo nuevo y no dejarse aplastar por lo ya dicho o la fuerza de la tradición. El tema de la delicada dosis necesaria entre memoria y olvido, entre cultura venida de la tradición y creación, es una de las temáticas del este extraordinario ensayo, pero también atraviesa la temática de su propuesta educativa. En Schopenhauer como educador, retorna a esta preocupación, la cultura entendida como acumulación, la exigencia aplastante de adaptación sobre la fuerza de la originalidad o autenticidad. ¿Cuál es el núcleo de una persona, su “centro”, cuando no le ha sido posible a una persona forjarse de acuerdo a sus propios sentidos, búsquedas, o 
necesidades? (entendiendo que no hay un centro único, que el sentido se mueve con uno, etc.). Cuando no le ha sido posible forjar tan siquiera un núcleo ni sabe qué es y todo el o ella es superficie adaptada a los usos, costumbres y modas de una sociedad. La verdadera cultura tiene que ver con este autoconocimiento que propendían los antiguos (gnothi seauton) ligada a la inquietud de sí como forma del cuidado (epimeleia heautou). Sobre esto no me voy a detener en particular, pero es obvio que en esto también Nietzsche sigue la gran tradición antigua de la filosofía como forma de existencia. El filósofo como modelo de la humanidad, el académico (éste es ejemplo más bien de lo contrario, es decir, de lo antifilosófico, del gesto aplastante y $\sin$ vida del conocimiento libresco que no nace de una necesidad interna o de una pasión). Se trata de que una vida filosófica no puede ser posible sin la búsqueda genuina de lo propio que hay en nosotros. Para esto el filósofo/a debe conectarse con sus preguntas a partir de generar inquietud de sí y desasosiego que nos lleva a la necesidad de autoconocimiento. Esto se genera a partir de una relación erótica o de enamoramiento con un maestro, en este caso simbolizado por la figura idealizada del filósofo Schopenhauer. Sabemos que Schopenhauer es uno de los grandes maestros de juventud de Nietzsche (que luego va abandonar, como lo hace a lo largo de su vida con muchos, propinándole duras críticas y considerándolo un filósofo representante del pesimismo metafísico). Lo conoció a través de sus libros, sabemos que encontró en un comercio de libros antiguos El mundo como voluntad y representación y una vez que comenzó a leer el libro no pudo dejar de leerlo, se enamoró de su filosofía. Tanto es así, que veremos en esta etapa que el modelo superior de humano es para Nietzsche, Schopenhauer, y los pasos que hay que seguir para producir el genio filosófico como modelo de la humanidad están dados por la educación recibida por el mismo Schopenhauer. Acá estamos hablando de un genio solitario, que se construye a sí mismo a espalda de las masas siguiendo el modelo de romanticismo alemán que tiene en esta etapa de juventud mucha influencia sobre Nietzsche. Schopenhauer es el ejemplo de una formación centrada en sí mismo y libre de toda razón utilitaria. Ahora, este genio de la humanidad a la que debe tender la educación como su fin 
más alto, trocará a lo largo de su obra, en la figura del "ultrahombre", como modelo- meta de superación del hombre en el estado actual de cosas. Por esto, creemos que en cierto sentido este genio de la humanidad o ultrahombre, será educado por todas las ideas centrales de la filosofía nietzscheana; la voluntad de poder, el amor fati, el nihilismo, la muerte de Dios, pero sobre todo por la idea del eterno retorno de lo mismo ${ }^{1}$. Esta es la idea más alta para ser enseñada tal y como dice en sus Fragmentos Póstumos. Porque es la idea que nos coloca en otra relación con nuestro tiempo y circunstancia y nos ayuda a afirmar la vida (amor fati) en el instante, con todo lo que este tiene (sobre la idea del eterno retorno ver mi libro: El eterno retorno de lo mismo o el terror a la historia, 2010). Todo esto nos hace acordar a las palabras de Séneca. La vida no debe estar en función de la escuela, sino la escuela en función de la vida. Lo que hay que educar en definitiva no es un genio musical o filosófico en un sentido académico...esto es para Nietzsche, un gran cerebro, una gran oreja. El especialista no debe ser el modelo de ser humano, pues es una visión mutilada de humanidad. El modelo de la humanidad es íntegro y se cría (término usado por Nietzsche en sus Fragmentos Póstumos) a sí mismo en la soledad con la ayuda de grandes genios, de grandes maestros que son los faros de la humanidad y que nos presentan en acto el estado al que debemos llegar. Se trata de maestros de la vida, como decíamos en otras circunstancias de "pedagogos de la humanidad"2 Formar la base para la cría de humanidad de excelencia es en lo que se centra la filosofía de la educación nietzscheana. Para esto debe derrotar los grandes ídolos de la cultura y educación de su época. Uno de ellos es el Estado. El Estado convertido en educador es un contrasentido, un absurdo. El Estado no piensa en lo mejor para la humanidad, sino en lo mejor para sí mismo, trabaja en función de la utilidad y lo que pretende generar son empleados de estado,

\footnotetext{
${ }^{1}$ A propósito de la idea del eterno retorno como la idea máxima que debe ser enseñada, hemos realizado un trabajo, ver: Diaz Genis Andrea, Calabria Robert: en "Filosofar-vivir a partir de la máscara y eterno retorno. Educando a un nuevo tipo de ser humano" Actualidad del pensamiento de Nietzsche, Montevideo, Comisión Sectorial de Divulgación científica, FHCE, UdelaR, 2012 (en prensa).

${ }^{2}$ Ver Díaz Genis, Andrea: "La filosofía como cura del alma y la educación para la sabiduría" en Montevideo, Revista Fermentario nro. 4, FHCE, UdelaR, 2010.
} 
burócratas, y no humanos plenos. La medida de la educación posible, permitida en este contexto, es aquella que esté acorde con esta utilidad que se traduce en dinero. No puede pensar una educación en la que haya una desproporción entre el tiempo que le lleva a la persona educarse y el dinero. El sujeto sólo debe educarse en forma acorde y proporcional a la ganancia o "utilidad". La inversión en educación debe ser proporcional a esta ecuación también. ¿De qué sirven estos sujetos que viven preparándose y no obtienen con ello ninguna utilidad en términos de réditos económicos? "Ser alguien..." (y todavía hoy resuenan estas palabras), significa ocupar un lugar en la sociedad, ganar dinero. Esto es lo que le debe proporcionar el Estado al sujeto a través de la educación. Nietzsche claro está, piensa en otra cosa, está pensando en educar y habilitar el máximo despliegue del posible desarrollo espiritual de la humanidad y esto sólo es posible, no para los más, sino para unos pocos. Unos pocos tocados por la varita mágica de la genialidad. Sin embargo esto no significa que no tengamos que seguir intentando y posibilitando el desarrollo en cada uno de esto genuino que hay en nosotros. Para esto, la relación con la propia época o circunstancia es fundamental. Tanto en este texto como en De la utilidad y la conveniencia de la historia para la vida, Nietzsche nos hace un llamado a ser intempestivos, fuera del tiempo. A no casarse con los valores de nuestro tiempo. En este momento los ídolos son el Estado, el dinero o la utilidad (expresada a través de la filosofía utilitarista), la burguesía como clase social, la historia, etc. Construirse a sí mismo fuera de tiempo es construirse a partir del oído fino de la interioridad. Es decir, frente a la exterioridad que exige adaptación, hay que bucear en el sí mismo, la voz de lo de lo propio e irrepetible, la voz en definitiva nos conecta con la vocación, entendida como llamado y presentada como pasión. Hay que vivir "con nuestra propia medida y nuestra propia ley" (p. 750). "Debemos mostrar por qué hemos nacido precisamente ahora" (p. 751). Debemos buscar nuestro "unicum". Esto que nos abre al horizonte que nos nombra y que a la vez nosotros nombramos o conquistamos con nuestra búsqueda y a partir de nuestras propias convencimientos. Esto, como ya dijimos, supone hundirse en el conócete a ti mismo délfico, que constituyó el centro de la vocación 
socrática no del todo bien reconocida por Nietzsche (sabemos de su relación conflictiva con la figura socrática). Escuchemos las hermosas palabras del poeta- filósofo que nos hace un llamado a la absoluta fidelidad al sí mismo y al desconocimiento de todo aquello que no nos nombra o desconoce en Schopenhauer como educador: "Tú misma no eres nada de eso, se dice el alma. Nadie puede construirte el puente sobre el cuál tú precisamente tienes que caminar sobre el río de la vida, nadie lo puede hacer, excepto tú y sólo tú” (p. 751).

Nos advierte Nietzsche, con inusitada hermosura y belleza expresiva, los innumerables caminos que nos pueden atraer y llevar a perdernos, pero hay un sólo camino que está hecho para nosotros mismos y nosotros debemos descubrir. Nos parece entonces, que si bien existe la idea del genio, no cabe duda, que hay algo que cada uno puede hacer en sí mismo, para encontrar este camino propio, es la vocación de todo ser, a la que estamos llamados en tanto humanos. El camino del ser y de la vocación que se le asocia, nos recuerda a nuestro pensador Don José Enrique Rodó que también promueve el desarrollo de una búsqueda personal singular a través de una educación que nos convierta al llamado de la vocación. Este autor hace a final de Motivos de Proteo, una distinción interesante entre convicción y conversión que viene al caso. La convicción sigue siendo una adhesión externa a la idea. La conversión, término que había sido usado en los orígenes de la filosofía por los griegos antes que en el cristianismo, fue traducido como metanoia y entendido como un cambio de posición y de relación con el mundo producto de una transformación radical. Creo que a este tema se refiere Nietzsche, se trata no sólo de cambio de postura del sujeto frente al mundo, sino conversión radical a un llamado que viene del interior. Mas toda verdadera conversión debe alcanzar la vida y no quedar sólo en la mente. Toda conversión interior supone una conquista exterior que responde al llamado de la autenticidad. No lo vamos a hacer aquí, pero nos parecería interesante realizar en algún momento un paralelo entre la obra rodoniana y la nietzscheana. En este sentido, como lo fue Ariel (el genio alado de La Tempestad de Shakespeare), el símbolo de la realidad más espiritual y auténtica, y maestro a su vez de la humanidad más joven (ver el 
libro Ariel de J. Enrique Rodó), los verdaderos maestros nietzscheanos, son también maestros de vida.

Tus verdadero educadores y moldeadores te descubren el verdadero sentido originario y la materia fundamental de tu ser, algo que es totalmente ineducable e inmoldeable, pero que en todo caso es también difícilmente accesible, y que esta atado y paralizado: los únicos que puede ser tus educadores son tus liberadores (p. 751-752)

Esta es una de las frases más felices e interesante de este texto. ¡Cuánta sustanciai El educador, en definitiva es un medium para el propio descubrimiento ¿Acaso esta no fue la función por excelencia de Sócrates en los albores de la Filosofía? M. Foucault decía referido a la enseñanza Socrática en su Hermenéutica del Sujeto (2011), algo que parecía un círculo vicioso en apariencia, pero que refiere a lo central de la actividad educativa socrática:

El maestro es quien se preocupa por la inquietud que el sujeto tiene con respecto a sí mismo y quien encuentra, en el amor que siente por su discípulo, la posibilidad de preocuparse por la preocupación de éste en relación consigo mismo. Al amar de manera desinteresada el joven, se erige, por lo tanto, en el principio y el modelo de la inquietud que éste debe tener por sí mismo en cuanto sujeto (p. 73)

Ahora, esta materia fundamental de nuestro ser, este ser del que debemos preocuparnos a partir de tener inquietud de sí, es ineducable... ¿qué significa esto? Este es el resto que nos permite considerar que el sí mismo no es sinonimia del yo... que el sí mismo, esto que somos, se despliega de una manera siempre misteriosa y no del todo autoconsciente. Dentro de nosotros, habita el misterio de nosotros mismos, un sí mismo que no puede ser sometido nunca del todo a la cultura ni a la razón. Esto nos recuerda a las tres tareas imposibles según $\mathrm{S}$ Freud: gobernar, psicoanalizar y educar. Siempre hay un resto ineducable y este "resto" es lo que nos permite, ser sujetos no del todo sujetables o sujetados. El resto, lo 
no idéntico, lo alter y otro, lo no susceptible de ser captado, analizado, lo que "no dice yo, sino que hace yo" (el cuerpo para Nietzsche, es el que se identifica con el sí mismo). Lo cierto, es que si hablamos de "verdadera educación", esta debe liberar no moldear. La educación que no moldea es precisamente la que permite que la persona se examine a sí mismo, pero tiene como centro de este examen, no la razón (logos) sino la vida misma (bios). Dice Sócrates en el Laques, otro texto de juventud, que mucho nos dice sobre la posición socrática del cuidado de sí en relación a la vida (bios):

Me parece que ignoras que, si uno se halla cerca de Sócrates en una discusión o se le aproxima dialogando con él, le es forzoso, aún si empezó a dialogar sobre cualquier otra cosa, no despegarse, arrastrado por él en el dialogo, hasta que lo sopese bien y suficientemente todo. Yo estoy acostumbrado a éste; sé que hay que soportar estas cosas, como también que estoy a punto de sufrir tal experiencia personal.

$\mathrm{Y}$ termina diciendo algo muy importante referido a aquellos que se acercan a él.

está deseoso de aprender mientras viva y no cree que la vejez por sí sola aporte sentido común. Para mí no resulta nada insólito ni desagradable exponerme a las pruebas de Sócrates, la charla no sería sobre los muchachos sino sobre nosotros mismos (p. 188c)

El foco de la enseñanza socrática es la propia vida. Sócrates es él mismo, básanos, "piedra de toque"3, que al entrar en diálogo con el otro, insta a que el discípulo examine su vida. El tema o problema que hay que sopesar es la vida misma que lleva el discípulo. Se trata de examinarse a sí mismo, siempre se trata de esto. ¿Y qué opina Laques acerca de esto...? Y allí aparece la clave de por qué, en definitiva es Sócrates el "tamiz" a través del cual los discípulos tienen que pasar. El maestro tiene una cualidad que no todos poseen, es un "musikos aner", posee una especie de "armonía

\footnotetext{
${ }^{3}$ Metáfora que hace referencia a la piedra que se usa para demostrar si algo es de oro o no lo es... 
ontológica", es decir, ofrece una coherencia entre lo que dice y hace. Veamos este texto:

Cuando oigo dialogar acerca de la virtud o sobre algún tipo de sabiduría a un hombre que es verdaderamente un hombre y digno de las palabras que dice, me complazco extraordinariamente al contemplar al que habla y lo que habla y lo que habla en recíproca conveniencia y armonía. Y me parece, en definitiva, que el hombre de tal clase es un músico que ha conseguido la más bella armonía, no en la lira ni en los instrumentos de juego, sino en armonizar en la vida real su propio vivir con sus palabras y hechos... (p. $188 \mathrm{~d})$

Ésta es la clave del magisterio socrático, habla de lo que vive, vive lo que habla. La filosofía es una forma de existencia. No debe ser jamás sólo una teoría no acompañada por una forma de vida. El bios es el foco de la enseñanza socrática y lo que por Sócrates vive lo que enseña y enseña lo que vive. El centro de la educación del filósofo como pedagogo de la Humanidad es también en Nietzsche la propia vida. Quién iba a decir este extraño paralelismo con un maestro de la Humanidad que ha sido tan criticado por Nietzsche como lo es Sócrates. Veamos más de de cerca lo que nos dice sobre el aporte educativo de la Filosofía, de cómo se educa lo genuino que hay en todos nosotros y como se cría al genio en la cultura. Pero antes de terminar con esta parte, no me queda más que citar esta tarea socrática de formación que nos recuerda Nietzsche para el bien de la humanidad:

$\mathrm{Y}$ éste es el secreto de toda formación: la formación no presta miembros artificiales, narices de cera, ojos con lentes correctores, -al contrario, lo que estos dones pueden ofrecer no es más que la imagen degradada de la educación. Porque la educación es liberación, limpieza de todas las malas hierbas, de los escombros, de los gusanos que quieren atacar los gérmenes de las plantas, es irradiación de luz y de calor... (p. 752) 
El principal aporte del filósofo educador, cuyo modelo es Schopenhauer, es en definitiva criar al humano para que sea humano. Para tener una verdadera educación, hay que pensar en función de la producción de la humanidad y no en teniendo como fin a la ciencia, el conocimiento, o la utilidad. Éstas deben estar en función de la producción de la humanidad y no viceversa. El filósofo de Nietzsche alcanza la vida, no se trata del erudito insano que acumula conocimiento, o del académico que persigue honores, ni del burócrata que trabaja por un sueldo. No hay sinonimia entre la verdadera filosofía y el profesor de filosofía como empleado del estado. La verdadera filosofía debe ser capaz de elevarse y superar a la insuficiencia de la época, debe ser inactual y a-institucional y por ello mismo estar en condiciones de aportar a la Humanidad. Sólo es Filósofo el que está en condiciones de dar ejemplo. Siguiendo la tradición antigua, la filosofía en Nietzsche constituye un modo de vida y un estilo de existencia. El filósofo dice quien es no sólo en cuanto piensa, sino en cuanto actúa como piensa y todo lo que hace dice quién es él, desde su vestimenta, su comida, hasta su modo de caminar. Como Schopenhauer, este filósofo sólo puede surgir fuera de la Universidad en la escuela de la vida. Pues la Universidad esta sometida a los designios del Estado y la filosofía no surge, muere, cuando está sometida a los designios de un estado de cosas o de un gobierno en particular. Se debe diferenciar la verdadera filosofía de la filosofía de profesores. La filosofía fue en la antigüedad una forma de existencia y el filósofo un pedagogo de la humanidad, dejó sus altos designios, para convertirse en teoría sin vinculación con la práctica, en escuela, sin exigirle ninguna transformación espiritual en su modo de vida al sujeto. Filosofía de doctrinas, historia de la filosofía, filosofía de profesores servil a los poderes existentes. Schopenhauer puede ser maestro, pues él es un filósofo fuera de la academia, no es filósofo a sueldo, puede desplegar su ser íntimo en relación con una necesidad nacida de su propio espíritu que no debe ni tiene por qué obedecer a las razones de estado. Para poder ejercer el dictum kantiano del SAPERE AUDE (atrévete a saber) que es por otra parte, lo que define a la 
humanidad en su estado de ilustración, el filósofo no debe ser funcionario a sueldo del Estado(en esto en Nietzsche se distancia radicalmente de Kant quien distingue un ejercicio privado y público de la razón). La filosofía “ofrece al ser humano un asilo en el que ninguna tiranía puede penetrar, la caverna de la interioridad, el laberinto del pecho; y esto fastidia a los tiranos". (p. 760).

Nada desgasta más que realizar algo por deber, por un imperativo categórico abstracto (ver mi Nietzsche versus Kant, 2004). En el Filósofo ideal que imagina Nietzsche, prima la voluntad de poder, que es poder de la voluntad, sobre el deber abstracto y universal kantiano. Prima lo personal, sobre la ley colectiva que expresa la voluntad de rebaño que somete al diferente y a las diferencias. No puedo desarrollar aquí una comparación entre un Kant y Nietzsche (cuestión que he hecho en otra oportunidad). Algo, sin embargo, iguala a ambos filósofos. No se es libre en el ámbito de la cultura, sin trabajo, sin sometimiento. Hay un período de sometimiento necesario a los grandes maestros y creadores de la Humanidad que establece el nivel y exigencia requeridos para llegar a niveles de excelencia. Antes de erigirse en supuesto creador, el sujeto debe someterse a la gran cultura y a los grandes maestros. El encontrar lo propio y lo genuino, el conquistar cierta libertad, no se da sin un periodo de sometimiento a las grandes creaciones y creadores (este punto es más desarrollado en Sobre el futuro de nuestras instituciones por Nietzsche y desplegado en la Pedagogía kantiana). De cualquier manera, a nosotros nos parece que en puntos fundamentales la pedagogía kantiana y nietzscheana puede ser complementarias. En definitiva, ambas tratan de la libertad y del alcance de la "mayoría de edad"(autonomía) por parte del sujeto, aunque por caminos y concepciones diferentes(donde Kant habla de razón, Nietzsche habla de cuerpo). Kant, al menos desde la perspectiva de Nietzsche, no dejó de ser un empleado del estado. Nietzsche eligió el camino de la libertad y de la soledad. A los 35 años (1879) se jubila por problemas de salud de la Universidad de Basilea. Se transforma de hecho, en lo que siempre quiso ser un filósofo libre y por su cuenta. No filosofa por pedido, ni por obligaciones, no filosofa por compromiso, filosofa porque tiene algo que 
decir. Filosofa porque se ha encontrado con la esfinge en su camino (como el Edipo Rey de la Tragedia de Sófocles) y ha resuelto el mayor de los enigmas. Esto lo precipita a su destino, el de ser el filósofo loco más lúcido que nos ha dado la historia, por esto puede ser en el siglo XIX, filósofo del siglo XXI, y como profeta anunciar lo que está por venir, la muerte de Dios, la muerte de los grandes ídolos de la modernidad, el anuncio del ultrahombre, aquel que no solo quiere lo acontecido, sino que quiere que se repita, el maestro del eterno retorno de lo mismo. Bien, ¿cómo se cría al ultrahombre, representado en esta etapa por el genio de Schopenhauer?

Es importante ver esto, en tanto que el genio de Schopenhauer, nos hace recordar al genio que todos nosotros tenemos adentro.

Cada cual lleva en sí, como el núcleo de su ser, una singularidad productiva; y cada uno se hace conciente de esa singularidad, aparece a su alrededor un extraño resplandor, el resplandor de lo extraordinario... (p. 764).

La pereza nos corroe la posibilidad de que emerja lo singular o genuino que hay en cada uno de nosotros...Los grandes pensadores, son aquellos que soportan la soledad y las grandes fatigas de la genialidad. Por esto pueden legislar y en definitiva "cambiar el valor de la moneda" (algo que el Oráculo de DELFOS, vaticinó que haría Diògenes el Cínico...). Es decir, tienen la voluntad de poder de instaurar una interpretación del mundo, de inaugurar y crear incluso "un mundo"... El genio, la última y suprema humanización, o incluso más allá, el ultrahombre, aquello que debe superar el estado de comprensión de lo humano en la actualidad. ¿Qué verdadera formación (Bildung) cría al genio? Nietzsche enumera ciertas características:

libre virilidad del carácter, temprano conocimiento de los seres humanos, completa ausencia de educación docta, de limitación patriótica, de necesidad de ganarse el pan, de toda relación con el Estado-en una palabra, libertad y nada más que libertad: el mismo elemento maravilloso y peligroso en el que los filósofos griegos tuvieron el derecho de crecer (p. 797). 
Al filósofo Schopenhauer se le dieron todos los elementos para crecer desde sí mismo sin someterse al orden, al Estado, a la Patria. Se le dieron las posibilidades de viajar, de experimentar y aprender por sí mismo antes que en los libros. Se le permitió antes que ser un docto, ser un verdadero ser humano... (nos dice Nietzsche, pues ¿cuándo un docto se ha convertido en verdadero ser humano?).

Nietzsche remplazará a Schopenhauer. Será el maestro de la humanidad venidera. Anunciará ideas capaces de ser comprendidas por lo menos doscientos años después. La crisis de la modernidad o la llamada posmodernidad, se hace patente a partir de Nietzsche. La posmodernidad, como dice Octavi Fullat, nace en 1900, época de la fecha de su muerte. La filosofía debe ser inactual para ser venidera. La educación lo mismo. ¿Acaso no estamos hoy bajo el imperio de los criterios del Estado o de la empresa, que tienen como estandarte medir la educación bajo los patrocinios del Dios Don Dinero...? La educación sometida a las leyes del mercado se mide bajo la vara de la eficacia. Ser más eficaz, más productivo, ayudar a que el sujeto sea un sujeto moldeable y adaptable al mercado, no es por supuesto aquello que los grandes pensadores imaginaron para la educación de la humanidad. Educar la humanidad, es el desafió más complejo y quizás una tarea imposible, aunque siempre necesaria. La filosofía pretendió ser la gran educadora de la Humanidad. Los verdaderos educadores de la humanidad son precisamente los grandes genios, que nos muestran hasta donde puede ir el despliegue de lo humano e incluso más allá de lo humano. Los ultrahombres, faros que nos permiten estar en tensión con nuestras insuficiencias para ser mejores. El rigor intelectual, la exigencia de disciplina no están reñidas con la libertad, siendo que ésta las reclama para sí. El tema aquí no es disciplina o libertad, pues no hay libertad sin rigor y sin disciplina. El problema fundamental y filosófico es para qué hay que educar. Hay que educar para hacernos mejores, para sacar lo mejor de nosotros mismos y para ello, no hay mejor que los mejores para enseñarnos. Este es el legado y la enseñanza de la filosofía de la educación nietzscheana. 


\section{Bibliografia}

DÍAZ, Genis Andrea. Nietzssche versus Kant. Montevideo, Actio 5, octubre de 2004 en http://www.fhuce.edu.uy/actio/Textos/5/AndreaDiaz.pdf.

. El eterno retorno de lo mismo o el terror a la historia. Montevideo: Editorial Ideas, 2010.

, A Puchet E. Inquietud de síy educación. Hacia un replanteo de la Filosofia de la educación I. Motevideo: Magró, 2010.

FOUCAULT, Michel. La Hermenéutica del Sujeto. Argentina: FCE, 2011.

NIETZSCHE, Friedrich. Consideraciones intempestivas III, Shopenhauer como educador en Obras Completas, Volumen I. Escritos de Juventud. Madrid: Editorial Técnos, 2011.

- Sobre el futuro de nuestras instituciones educativas. en Obras Completas.

Volumen I. Escritos de Juventud. Madrid: Editorial Técnos, 2011.

. Nietzsche, Friedrich, De la utilidad y la conveniencia de la Historia para la vida

en Obras Completas. Volumen I. Escritos de Juventud. Madrid: Editorial Técnos, 2011.

PLATÓN. Laques en Diálogos Tomo I. Madrid: Gredos, 1981. 